RESEARCH ARTICLE

\title{
In vitro regeneration of shoots from Garcinia quaesita leaf explants
}

\author{
A.F.R. Farzana, R.M.I.E.K. Bandara, P. C. Aluwihare and J.P. Eeswara* \\ Department of Crop Science, Faculty of Agriculture, University of Peradeniya, Peradeniya.
}

Revised: 21 January 2010; Accepted: 23 April 2010

\begin{abstract}
Garcinia quaesita is an economically valuable plant, which has a huge demand in the local as well as the export market. Lack of good quality products throughout the year coupled with the unavailability of quality planting material is a major drawback in the cultivation of G. quaesita. Thus, in the present study large scale multiplication of G. quaesita using tissue culture techniques was investigated. Leaves and nodal segments were obtained from plants maintained under green house conditions. The effect of benzylaminopurine (BAP) and naphthalene acetic acid (NAA) on shoot initiation from leaf explants and the effect of BAP on proliferation of nodal segments were investigated. The effect of indole-3-butyric acid (IBA) and NAA on rooting of micropropagated shoots was also studied.
\end{abstract}

Shoots were successfully initiated by culturing in vitro grown leaves and immature leaves from greenhouse grown plants on Murashige and Skoog (MS) medium supplemented with 5.0 or $10.0 \mathrm{mg} \mathrm{L}^{-1}$ BAP in complete darkness. Within 24 weeks, $9-12$ shoots could be produced from a single leaf explant (10 mm x10 mm). Further growth of G. quaesita nodal explants could be achieved by culturing on MS medium supplemented with $20.0 \mathrm{mg} \mathrm{L}^{-1}$ BAP. Rooting could not be achieved on MS medium supplemented either with IBA $\left(1.0,5.0,10.0 \mathrm{mg} \mathrm{L}^{-1}\right)$ or NAA $\left(1.0,5.0,10.0 \mathrm{mg} \mathrm{L}^{-1}\right)$.

Keywords: Garcinia quaesita, micropropagation, shoot induction.

\section{INTRODUCTION}

Garcinia quaesita Pierre, which belongs to the family Clusiaceae, is an evergreen lactiferous tropical tree. It produces yellowish pumpkin shaped, medium sized fruits ${ }^{1}$. It is grown in many parts of the South and SouthEast Asia and western side of the Indian peninsula ${ }^{2}$. G. quaesita is commonly known as brindle berry, Malabar tamarind (English) and was earlier known as G. cambogia, G. gummi-guta (L.), Cambogia gummi-guta L. and G. gutta L. ${ }^{3}$. Two Garcinia ('Goraka') species are found in India and Sri Lanka, the fruits of which are used for culinary purposes. G. quaesita Pierre (red fruited) is native to India while G. zeylanica Roxb (yellow fruited) is native to Sri Lanka.

G. quaesita Pierre is an economically valuable species. The fruit is used as a spice/condiment and in indigenous medicine. Hydroxycitric acid (HCA) is the primary acid found in its fruit and rind. In Indian folk tradition, G. quaesita has been prescribed for ailments such as rheumatism and bowel complaints. The rind and extracts are often used as ingredients in Sri Lankan curry dishes and as a condiment. Both G. quaesita and extracted HCA are widely available in North-America as a component in many commercial dietary supplements. It is also valued for its industrial use, as the dried rind is used for polishing gold and silver and also in the coagulation of rubber latex. The wood is used for posts, cheap boxes and split and the latex is used for painting and dyeing.

Although the fruits of this tree has a huge demand in the local as well as in the export markets, it has not been planted on a large scale, and the Garcinia products come to the market only through collection from the forests and home gardens. Lack of availability of reliable good quality products throughout the year is the major constraint for developing the Garcinia industry.

At present, G. quaesita is propagated totally by seeds. However, low germination percentage, recalcitrant nature of the seeds, seasonal flowering behaviour and the dioecious nature of the tree, as well as the long

\footnotetext{
${ }^{*}$ Corresponding author (jpe@pdn.ac.lk)
} 
juvenile period of the seedling plants limit propagation by seeds. Conventional vegetative propagation methods such as budding, grafting and layering have been tried for $G$. quaesita. However, the use of conventional methods in improving desired quality characters and in mass propagation is both time and labour consuming. The culture of isolated plant cells, tissues and organs in a sterile environment is a potentially useful tool in horticultural investigations. Rapid clonal multiplication of desired plant types is one of many applications of plant tissue culture which can also act as a tool for quality enhancement. Therefore, micropropagation techniques can be used to overcome the above-mentioned problems in the propagation and quality improvement of Garcinia.

Although there is no evidence of successful studies on micropropagation of G. quaesita, techniques have been developed for closely related species such as Mangosteen ( $G$. mangostana L. $)^{4-8}$ and $G$. indica ${ }^{9,10}$. Regeneration of G. mangostana by culturing leaves has been achieved on woody plant medium enriched with $20.0 \mu \mathrm{M} \mathrm{BAP}^{5}$. Moreover, leaves from field-grown seedlings produced an average of 45 shoot buds per leaf after 50 days of culture ${ }^{5}$, compared with 8 shoot buds per leaf from in vitro shoots. Furthermore, $5.0 \mathrm{mg} \mathrm{L}^{-1}$ of BAP was reported as the optimal level for shoot bud development from G. mangostana seedling leaf explants ${ }^{5}$. At concentrations above $5.0 \mathrm{mg} \mathrm{L}^{-1} \mathrm{BAP}$, shoot buds produced were clustered and stunted.

Taking all these into consideration, the production of clonal plants of $G$. quesita via axillary shoot formation using nodal explants and direct and indirect shoot bud regeneration using leaf cultures was investigated. In preliminary studies nodal explants collected from field grown elite trees were used ${ }^{11}$. However, cultures could not be established successfully due to very high microbial growth. Therefore, it was decided to develop the technique first using explants collected from in vitro and greenhouse grown seedlings.

Furthermore, in the preliminary studies the combined effect of Benzylaminopurine (BAP) $\left(0.0-5.0 \mathrm{mg} \mathrm{L}^{-1}\right)$ and Naptheline acetic acid (NAA) or Indole-3-butyric acid (IBA) $\left(0.0-1.0 \mathrm{mg} \mathrm{L}^{-1}\right)$ on callus initiation from G. quaesita leaf explants was investigated and a higher percentage $(80 \%)$ of good calli production was observed in the Murashige \& Skoog (MS) medium supplemented with $1.0 \mathrm{mg} \mathrm{L}^{-1} \mathrm{BAP}$ and $0.5 \mathrm{mg} \mathrm{L}^{-1} \mathrm{NAA}^{11,12}$.

Thus, in the present study shoot bud regeneration from leaf explants and multiplication of nodal segments were investigated. Explants were obtained from both in vitro and greenhouse grown plants and cultured on MS medium supplemented with different levels of BAP and a combination of BAP and NAA. Shoot proliferation from nodal explants was investigated on MS medium supplemented with different levels of BAP.

\section{METHODS AND MATERIALS}

Source of explants: Shoot bud regeneration from leaf and nodal explants was investigated separately on leaves obtained from the shoots of in vitro grown seedlings and greenhouse grown (in vivo), 2-3 year-old seedlings.

Sterilization: Leaves and nodal segments from in vitro grown seedlings were sterilized by shaking with $5.0 \%$ bleach (Clorox, FFM Marketing) for 5 min followed by rinsing thrice with sterile distilled water.

Leaves taken from greenhouse grown plants were rinsed thoroughly with liquid soap (Teepol, Lankem) several times followed by final rinsing in tap water. The leaves were dipped in a $0.1 \%$ Ridomil solution for $2 \mathrm{~h}$ and brought into the lamina flow cabinet. It was then sterilized by shaking with $10.0 \%$ bleach (sodium hypochlorite) for 10 min with 2-3 drops of a surfactant (Tween 20-Polyoxyethelene sorbitan monolaurate) followed by rinsing with sterile water and again shaking with $10.0 \%$ bleach alone for $10 \mathrm{~min}$. Then the leaves were thoroughly washed thrice with sterile distilled water and dipped in $0.2 \%$ streptomycin for $1 \mathrm{~h}$.

Nodal segments obtained from the greenhouse grown plants were also sterilized by using the same procedure for leaf explants. However, the contamination rate was high. Therefore, it was decided to shake nodal segments in $0.5 \% \mathrm{HgCl}_{2}$ for 3 min before dipping in streptomycin for $1 \mathrm{~h}$ to reduce contamination.

Shoot bud regeneration from leaf explants of G. quaesita: Approximately $1 \mathrm{~cm}^{2}$ sized pieces of the leaf lamina were excised from the leaves, with each piece including a portion of the main vein. They were placed on MS medium ${ }^{13}$ supplemented with 3 different levels of BAP (2.0, 5.0, $\left.10.0 \mathrm{mg} \mathrm{L}^{-1}\right)$ and $1.0 \mathrm{mg} \mathrm{L}^{-1}$ BAP combined with $0.5 \mathrm{mg} \mathrm{L}^{-1}$ NAA.

Leaves were placed in such a way, that the abaxial side (underside) of the leaf explant could touch the medium. The cultures were incubated at $25^{\circ} \mathrm{C}$, under complete darkness and subcultured after 8 wks to the same media. Visual observations were made weekly and the formation of shoots or callus was recorded at the time of subculturing. For the analysis of data, level of callus formation was recorded using a scale of 0-3 
(0: no response, 1: callus just detected, 2 : medium callus formation, 3 : high callus formation). The callus initiated was isolated and transferred to MS medium containing $5.0 \mathrm{mg} \mathrm{L}^{-1} \mathrm{BAP}$ for shoot regeneration.

Once the shoots were differentiated into stem and bud/leaf, they were gradually transferred to light and continuously incubated under light (16/8 h at $1000 \mathrm{lux})$ at $25 \pm 1{ }^{\circ} \mathrm{C}$.

Shoot proliferation of $G$. quaesita from nodal explants: Nodal segments were isolated from the sterilized shoots and were cultured upright on MS medium supplemented with 5.0, 10.0 and $20.0 \mathrm{mg} \mathrm{L}^{-1}$ BAP separately.

The cultures were incubated at $16 \mathrm{~h} / 8 \mathrm{~h}$ light/dark, 1000 lux at $25 \pm 1{ }^{\circ} \mathrm{C}$ and formation of shoots was recorded at weekly intervals. These cultures were subcultured at $8 \mathrm{wk}$ intervals to the same medium.

Effect of NAA, IBA and sucrose on rooting of micropropagated plantlets: The production of roots in shoots obtained from leaf explants and nodal segments was examined on MS and half MS medium supplemented with sucrose at different concentrations (3\% and 5\%) with 3 different levels (1.0, 5.0, $\left.10.0 \mathrm{mg} \mathrm{L}^{-1}\right)$ of IBA or NAA.
Data analysis: In each experiment, each treatment consisted of 25 culture tubes and was replicated thrice. Results of callus production were analyzed using Kruskal-Wallis and Friedmann Tests in Minitab 14 statistical package. Shoot production values, response and survival rates were analyzed using ANOVA and CATMOD procedures in SAS 9.1 statistical package.

\section{RESULTS}

\section{Shoot bud regeneration from leaf explants of G. quaesita}

Irrespective of the origin (in vitro/greenhouse) and the maturity of the explant, MS medium supplemented with $1.0 \mathrm{mgL}^{-1} \mathrm{BAP}$ and $0.5 \mathrm{mgL}^{-1} \mathrm{NAA}$ produced significantly $(\alpha=0.05)$ more calli compared to the rest of the media compositions (Table 1). Furthermore, immature leaf explants obtained from greenhouse grown seedlings and in vitro seedlings produced more calli $(\alpha=0.05)$ compared to the mature leaves on this medium. In vitro grown leaves produced no calli on the medium supplemented with $10 \mathrm{mg} \mathrm{L}^{-1}$ BAP.

Direct shoot bud regeneration from in vitro grown and immature leaf explants was observed on MS medium supplemented with 5.0 and $10.0 \mathrm{mg} \mathrm{L}^{-1}$ BAP

Table 1: Effect of growth regulator concentration, origin and maturity of the tissues on callusing and shoot bud regeneration from leaf explants of G. quaesita at 24 weeks after culturing

\begin{tabular}{|c|c|c|c|c|c|}
\hline \multirow[b]{2}{*}{ Type of leaves } & \multirow[b]{2}{*}{$\begin{array}{l}\text { Growth regulator } \\
\text { concentration } \\
\mathrm{mg} \mathrm{L}^{-1}\end{array}$} & \multicolumn{2}{|c|}{ Initiation of callus } & \multicolumn{2}{|c|}{ Shoot bud regeneration } \\
\hline & & $\begin{array}{l}\text { Average score } \\
\text { (out of } 3) \pm \mathrm{SE}\end{array}$ & $\begin{array}{c}\text { Percentage of } \\
\text { explants producing } \\
\text { calli }(\%)\end{array}$ & $\begin{array}{l}\text { Average number of } \\
\text { shoots per explant }\end{array}$ & $\begin{array}{c}\text { Percentage of } \\
\text { explants producing } \\
\text { shoots buds }\end{array}$ \\
\hline \multirow[t]{4}{*}{ In vitro leaves } & $\begin{array}{l}1 \mathrm{BAP}+ \\
0.5 \mathrm{NAA}\end{array}$ & $2.44 \pm 0.86$ & 90.00 & 0.00 & 0.00 \\
\hline & $2 \mathrm{BAP}$ & $1.07 \pm 0.27$ & 74.00 & 0.00 & 0.00 \\
\hline & $5 \mathrm{BAP}$ & $1.00 \pm 0.00$ & 53.00 & $6.50 \pm 1.50$ & 14.00 \\
\hline & $10 \mathrm{BAP}$ & 0.00 & 0.00 & $9.00 \pm 2.50$ & 30.00 \\
\hline \multirow{4}{*}{$\begin{array}{l}\text { Mature leaves } \\
\text { from greenhouse } \\
\text { plants }\end{array}$} & $\begin{array}{l}1 \mathrm{BAP}+ \\
0.5 \mathrm{NAA}\end{array}$ & $1.33 \pm 0.52$ & 55.00 & 0.00 & 0.00 \\
\hline & 2 BAP & 0.00 & 0.00 & 0.00 & 0.00 \\
\hline & $5 \mathrm{BAP}$ & $1.00 \pm 0.12$ & 25.00 & 0.00 & 0.00 \\
\hline & $10 \mathrm{BAP}$ & $2.00 \pm 0.25$ & 22.00 & 0.00 & 0.00 \\
\hline \multirow{4}{*}{$\begin{array}{l}\text { Immature leaves } \\
\text { from greenhouse } \\
\text { plants }\end{array}$} & $\begin{array}{l}1 \mathrm{BAP}+ \\
0.5 \mathrm{NAA}\end{array}$ & $2.51 \pm 0.75$ & 100.00 & 0.00 & 0.00 \\
\hline & $2 \mathrm{BAP}$ & $1.17 \pm 0.39$ & 80.00 & 0.00 & 0.00 \\
\hline & $5 \mathrm{BAP}$ & $1.50 \pm 0.50$ & 40.00 & $8.00 \pm 2.50$ & 30.00 \\
\hline & $10 \mathrm{BAP}$ & $1.00 \pm 0.00$ & 20.00 & $12.17 \pm 5.50$ & 70.00 \\
\hline
\end{tabular}


Table 2: Shoot proliferation from in vitro nodal segments of G. quaesita on MS medium supplemented with different BAP concentrations

\begin{tabular}{|c|c|c|c|c|}
\hline \multirow{2}{*}{$\begin{array}{l}\text { BAP } \\
\text { concentration } \\
\mathrm{mg} \mathrm{L}^{-1} \mathrm{BAP}\end{array}$} & \multicolumn{3}{|c|}{ Average no. of new shoots per explant } & \multirow{2}{*}{$\begin{array}{l}\text { Percentage } \\
\text { of explants } \\
\text { responded }(\%)\end{array}$} \\
\hline & After 8 weeks & After 16 weeks & After 24 weeks & \\
\hline 5.00 & $0.00 \pm 0.00$ & $1.00 \pm 0.00$ & $1.00 \pm 0.00$ & 12.50 \\
\hline 10.00 & $1.00 \pm 0.00$ & $1.00 \pm 0.00$ & $1.00 \pm 0.00$ & 36.00 \\
\hline 20.00 & $1.00 \pm 0.00$ & $1.00 \pm 0.00$ & $1.75 \pm 0.50$ & 78.00 \\
\hline
\end{tabular}

[Figure 1(i)]. Furthermore, the average number (9-12) of shoot buds produced on the medium supplemented with $10.0 \mathrm{mg} \mathrm{L}^{-1}$ BAP was significantly higher $(\alpha=0.05)$ than that $(6-8)$ of the medium supplemented with $5.0 \mathrm{mg} \mathrm{L}^{-1}$ BAP (Table 1). The media supplemented with $2.0 \mathrm{mg} \mathrm{L}^{-1}$ BAP and $1.0 \mathrm{mg} \mathrm{L}^{-1} \mathrm{BAP}+0.5 \mathrm{mg} \mathrm{L}^{-1} \mathrm{NAA}$ did not produce any shoot buds even 48 weeks (results are given only for 24 weeks) after culturing of leaf explants. The mature leaf explants produced only callus but there was no shoot bud regeneration (Table 1).

The initiated calli, transferred to the MS medium supplemented with $5.0 \mathrm{mg} \mathrm{L}^{-1}$ BAP also produced shoots [Figure 1(v)] showing the possibility of indirect organogenesis of G. quesita, which will be useful in crop improvement programmes.

\section{Shoot proliferation from nodal explants of G. quaesita}

Shoot elongation and proliferation from in vitro nodal explants were observed on $20.0 \mathrm{mg} \mathrm{L}^{-1}$ BAP supplemented medium and they produced an average of $1.75 \pm 0.50$ shoots per explant. These results were observed from $78 \%$ of the total cultures after 24 weeks (Table 2 ).

In agreement with the results observed for nodal explants obtained from in vitro seedlings, the highest percentage of shoot development in nodal explants obtained from greenhouse grown plants (in vivo seedlings) was also observed in the medium supplemented with $20.0 \mathrm{mg} \mathrm{L}^{-1}$ BAP (results not given). However, nodal segments obtained from greenhouse grown plants showed a very high contamination rate even 16 weeks after establishment. Thus, it was very difficult to establish nodal cultures from the explants taken from greenhouse grown plants.

\section{Effect of NAA, IBA and sucrose on rooting}

None of the micropropagated shoots produced any roots either on full or half strength MS medium supplemented either with NAA $\left(1.0,5.0,10.0 \mathrm{mg} \mathrm{L}^{-1}\right)$ or IBA $(1.0,5.0$, $10.0 \mathrm{mg} \mathrm{L}^{-1}$ ) at two different concentrations (3 and 5\%) of sucrose.

\section{DISCUSSION}

In vitro explants are more reliable in preventing plantborne contaminations during in vitro studies ${ }^{14}$. Therefore, in the present study leaves and nodes from in vitro grown seedlings were utilized. However, the leaf explants taken from the greenhouse grown plants also showed negligible rate of contamination, whereas the survival rate $(95 \%)$ was not significantly different from explants obtained from in vitro grown seedlings $(96.67 \%)$. In contrast to leaf cultures, the survival rate of the nodal cultures from the in vitro explants was higher $(100 \%)$ than the nodal cultures of greenhouse grown plants. Therefore, use of in vitro explants was worthwhile with respect to nodal cultures, where reducing contamination is challenging.

In the present study a higher average of 12 shoots per leaf explant was obtained after 24 weeks of culture from immature leaves obtained from greenhouse grown seedlings (Table 1) and a lower average of 9 shoots per explant was obtained from in vitro leaves (Table 1), which is on par with the results of previous studies ${ }^{6}$. Irrespective of the type of explant used, age plays a critical role in determining the response of in vitro cultures. Older tissues produce either root forming or non regenerable calli $^{15}$. In agreement with the above observation, the present study also showed that immature and mature leaves performed differently with regard to induction of callus and shoot regeneration. This work showed that the immature leaves were better in shoot bud induction as well as for callus initiation (Table 1). Physiological and ontogenic state of the explant is known to affect the shoot organogenic capacity ${ }^{5}$. Loss of competence of mature explants has been attributed to progressive specialization of the tissue, which reduces the plasticity and capability of the cells to dedifferentiate ${ }^{16}$. The age of leaves obtained even from mature plants had been used successfully ${ }^{17,18}$. Thus, it may be possible that once a suitable sterilization procedure is developed these steps can successfully be applied to young leaves taken from field grown trees. However, the physiological state of the plant from which the explant is taken should be considered. 

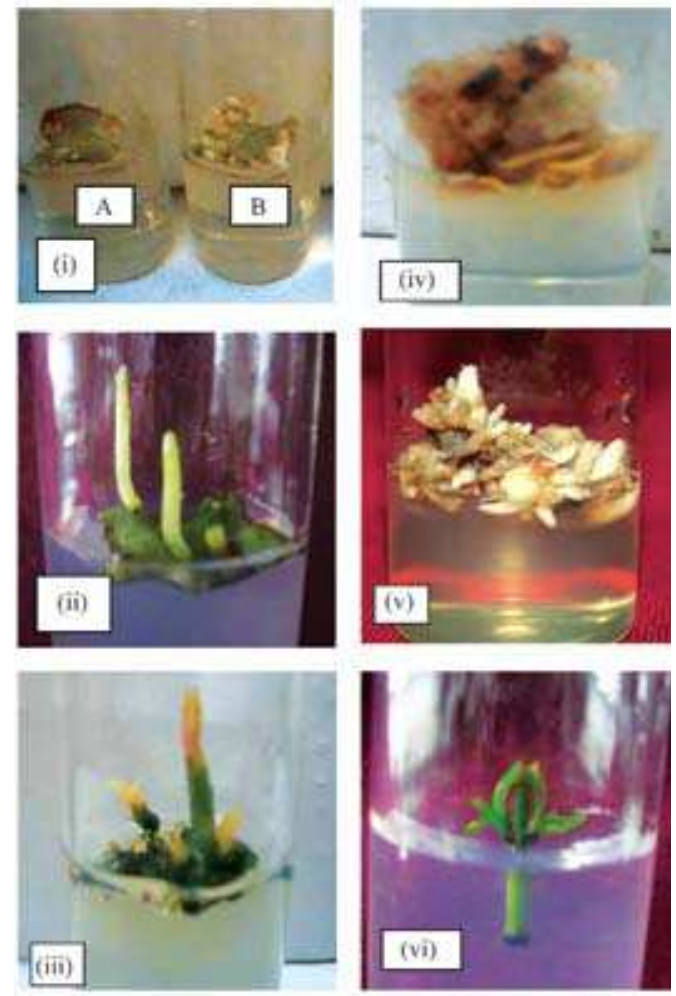

Figure 1: In vitro cultures of G. quaeista (i) Shoot initiation from leaf explants cultured on MS medium supplemented with 5 (A) and 10 (B) $\mathrm{mg} \mathrm{L}^{-1} \mathrm{BAP}$, (ii \& iii) bud and leaf formation from shoots, (iv) callus initiation from leaf explants cultured on MS medium supplemented with $1 \mathrm{mg} \mathrm{L}^{-1}$ BAP and $0.5 \mathrm{mg} \mathrm{L}^{-1} \mathrm{NAA}(\mathrm{v})$ shoot formation from calli on MS medium supplemented with $5 \mathrm{mg} \mathrm{L}^{-1} \mathrm{BAP}$ (vi) elongation of nodal explant on MS medium supplemented with $20 \mathrm{mg} \mathrm{L}^{-1}$ BAP.

The developmental age of the leaf in comparison to other leaves, and the position of the leaf from where the explants are excised could determine the in vitro response. Leaf sections obtained from the basal portions of the youngest leaves are the best for regeneration compared to the sections taken away from the leaf base ${ }^{17}$. G. quaesita leaves are linear in shape and there is much variation in the position of the explant from the leaf base. Therefore, in future, this factor too may be considered in reducing variation of performance within the same treatment.

A wound response in the presence of BAP at the time of culture was found to be essential for shoot bud induction in G. mangostana ${ }^{6}$. In contrast, in the present study shoots were formed not only from the cut edges, but also from the surface of the leaf explants [Figure 1(i)].

Dosage of the cytokinin in the culture medium is known to be critical for shoot regeneration. In many studies, BAP was found to be more potent compared to other cytokinins in shoot formation ${ }^{19}$. Superiority of BAP for shoot induction may be attributed to the ability of plant tissues to metabolize BAP more readily than other synthetic growth regulators or to the ability of BAP to induce production of natural hormones such as zeatin within the tissue ${ }^{19}$. The effect of BAP in inducing multiple shoots has also been reported in G. mangostana ${ }^{5,7}$.

Shoots from G. mangostana leaf explants have been regenerated on a medium supplemented with $20 \mu \mathrm{M}$ BAP and further growth of regenerated shoots was obtained on a medium containing $5 \mu \mathrm{M} \mathrm{BAP}{ }^{6}$. This factor can be considered in further studies since in the present study the regenerated shoots were continuously maintained in the same media composition, where the growth rate was very low.

Incorporation of NAA in the medium has shown a deleterious effect on shoot bud formation and encouraged callus formation in G. indica ${ }^{9}$. A similar effect of NAA is also reported in G. mangostana ${ }^{7,8}$. On the contrary, a positive effect of NAA in morphogenetic responses of G. indica seeds has also been reported ${ }^{10}$. However, in the present study, the results on G. quaesita was in agreement with that of a previous study ${ }^{9}$ where callus formation was enhanced by addition of NAA to the medium. The variable response of different species to auxin supplemented media may be due to different endogenous levels of auxins. Inhibition of shoot formation may be due to the action of auxins accumulated in the explants ${ }^{20}$.

Direct regeneration helps in clonal propagation, whereas indirect regeneration through the intermediate phase of callus or undifferentiated cells could act as a source of variation for crop improvement. Therefore, regeneration of shoots from both direct and indirect pathways in this study would be of much use in applying these protocols according to requirement, depending on whether the aim is clonal propagation or creating new phenotypes through variation.

In the present study, a higher percentage of nodes grown on MS medium supplemented with $20 \mathrm{mg} \mathrm{L}^{-1}$ BAP showed elongation and further growth of shoots compared to the other media supplemented with 5 and $10 \mathrm{mg} \mathrm{L}^{-1}$ BAP (Table 2). Furthermore, production of new shoots from nodal segments occurred only in $20 \mathrm{mg} \mathrm{L}^{-1}$ BAP supplemented medium. The dosage of the cytokinin in the culture medium is critical not only for shoot organogenesis, but also for the elongation of the shoots. Increase in BAP concentration beyond the optimal levels led to a decrease in shoot length and aggregation of shoot buds ${ }^{4,9}$. Exposure of explants to higher BAP concentrations during induction phase may lead to accumulation of cytokinins, which inhibits further shoot growth. This decrease in shoot length and aggregation of 
shoot buds can be overcome by incorporating charcoal into the culture medium ${ }^{21}$. Elongation of the induced shoots from seed segments of $G$. indica has been achieved on the MS basal medium containing $0.2 \%$ activated charcoal ${ }^{9}$.

It is reported that in some Garcinia species IBA has induced longer and thinner roots in a higher number of explants compared to thick stunted roots produced on NAA supplemented media ${ }^{5,9}$. Rooting of G. mangostana shoots has been induced with $1 \mathrm{mg} \mathrm{L}^{-1} \mathrm{IBA}$ when the shoots reached a height of $10-15 \mathrm{~mm}$ and were established in a vermiculite/sand mix in pots ${ }^{5,6}$. Shoots from leaves of seedlings and mature mangosteen trees, measuring more than $2 \mathrm{~cm}$ when rooted with an acute auxin treatment and plantlets derived from seedling leaf explants have been successfully acclimatized and established in soil ${ }^{5,6}$. However, in the present study, rooting of micropropagated shoots could not be achieved either with IBA or NAA at $3 \%$ or $5 \%$ sucrose concentration both in MS and half MS media. The higher concentrations of NAA $\left(10 \mathrm{mg} \mathrm{L}^{-1}\right)$ were toxic to the growth of shoots. Thus, further research is needed to find out a suitable treatment for induction of roots in micropropagated shoots of G. quaesita .

\section{Acknowledgement}

The authors gratefully acknowledge the Sri Lanka Council for Agricultural Research Policy for providing funds for this study.

\section{References}

1. Woodward J.R. (2002). G. cambogia. Fact sheet. http:// chppm-www.apgea.army.mil/dhpw/Wellness/dietary/ Factsheets/GarciniaCambogia.pdf. Accessed on 04 November 2006.

2. Anonymous (2006). What is Garcinia Cambogia? www. plantnames.unimelb.edu.au/Sorting/Garcinia.html. Accessed on 04 November 2006.

3. Porcher M.H. (2004). Sorting Garcinia names. The University of Melbourne multilingual multiscript plant name database. www.plantnames.unimelb.edu.au/Sorting/ Garcinia.html. Accessed on 04 November 2006.

4. Goh H.K.L., Rao A.N. \& Loh C.S. (1990). Direct shoot bud formation from leaf explants of seedlings and mature mangosteen Garcinia mangostana L. trees. Plant Science (Limerick) 68(1): 113-122.

5. Goh H.K.L., Rao A.N. \& Loh C.S. (1988). In vitro plantlet formation in mangosteen Garcinia mangostana L. trees. Annals of Botany (London) 61(1): 87-94.

6. Goh C.J., Lakshmanan P. \& Loh C.S. (1994). High frequency direct shoot bud regeneration from excised leaves of mangosteen (Garcinia mangostana L.). Plant Science (Limerick). 101(2): 173-180.
7. Huang L.C., Huang B.L., Wang C.H., Kuo C.I. \& Murashige T. (2000). Developing an improved in vitro propagation system for slow-growing species using Garcinia mangostana L. (mangosteen). In Vitro Cellular and Development Biology 36(6): 501-504.

8. Normah M.N., Nor-Azza A.B. \& Aliudin R. (1995). Factors affecting in vitro shoot bud proliferation and ex vitro establishment of mangosteen. Plant Cell Tissue and Organ Culture 43(3): 291-294.

9. Malik S.K., Chaudhury R. \& Kalia R.K. (2005). Rapid in vitro multiplication and conservation of Garcinia indica: a tropical medicinal tree species. Scientia Horticulturae 106(4): 539-553.

10. Kulkarni M.D. \& Deodhar M.A. (2002). In vitro regeneration and hydroxycitric acid production in tissue cultures of Garcinia indica Chois. Indian Journal of Biotechnology 1(3): 301-304.

11. Bandara P.U.R.K. (2002). In vitro propagation of "goraka" (Garcinia quaesita). B. Sc. Dissertation. Faculty of Agriculture, University of Peradeniya, Peradeniya.

12. Bandara R.M.I.E.K. (2007). In vitro propagation of "goraka" (Garcinia quaesita). B. Sc. Dissertation. Faculty of Agriculture, University of Peradeniya, Peradeniya.

13. Murashige T. \& Skoog F. (1962). A revised medium for rapid growth and bioassays with tobacco tissue cultures. Physiologia Plantarum 15(3): 473-497.

14. Leifert C., Morris C.E. \& Waites W.M. (1994). Ecology of microbial saprophytes and pathogens in tissue culture and field grown plants: reasons for contamination problems in vitro. Critical Reviews in Plant Sciences 13(2):139183.

15. Vasil V. \& Vasil I.K. (1984). Embryogenesis. In: Cell Culture and Somatic Cell Genetics of Plants, Vol. 1 (Ed. I. K. Vasil), pp. 1-12, Academic Press, New York.

16. Abdullah A.R., Yeoman M.M. \& Grace J. (1987). Micropropagation of mature calabrian pine (Pinus brutia Ten.) from fasicular buds. Tree Physiology 3(2):123-136.

17. Haydu Z. \& Vasil I.K. (1981). Somatic embryogenesis and plant regeneration from leaf tissues and anthers of Pennisetum purpureum Schum. Theoretical and Applied Genetics 59(5): 269-73.

18. Ho W. \& Vasil I.K. (1983). Somatic embryogenesis in sugarcane (Saccharum officinarum L.) I. the morphology and physiology of callus formation and ontogeny of somatic embryogenesis. Protoplasma 118(3): 169-80.

19. Zaerr J.B. \& Mapes M.O. (1982). Action of growth regulators. In: Tissue Culture in Forestry (Eds. J.M. Bonga and D.J. Durzan), pp. 231-255, Martinus Nijhoff/Dr. W. Junk Publishers, The Hague, The Netherlands.

20. Marks T.R. \& Simpson S.E. (1994). Factors affecting shoot development in apically dominant Acer cultivars in vitro. Journal of Horticultural Science 69(3): 543-551.

21. Fridborg G., Pederson M., Landstrom L. \& Eriksson T. (1978). The effect of activated charcoal on tissue cultures: adsorption of metabolites inhibiting morphogenesis. Physiologia Plantarum 43(2): 104-106. 